University of Nebraska - Lincoln

DigitalCommons@University of Nebraska - Lincoln

Nebraska Cooperative Fish \& Wildlife Research Nebraska Cooperative Fish \& Wildlife Research Unit -- Staff Publications

2016

\title{
Biological invasions, ecological resilience and adaptive governance
}

Brian C. Chaffin

University of Montana, brian.chaffin@umontana.edu

Ahjond S. Garmestani

National Risk Management Research Laboratory, garmestani.ahjond@epa.gov

David G. Angeler

Swedish University of Agricultural Sciences, david.angeler@slu.se

Dustin L. Herrmann

Oak Ridge Institute for Science and Education Research Participant Program with the United States

Environmental Protection Agency, herrmann.dustin@epa.gov

Craig A. Stow

National Oceanic and Atmospheric Administration, craig.stow@noaa.gov

Follow this and additional works at: https://digitalcommons.unl.edu/ncfwrustaff

a next page for additional authors

Part of the Aquaculture and Fisheries Commons, Environmental Indicators and Impact Assessment

Commons, Environmental Monitoring Commons, Natural Resource Economics Commons, Natural

Resources and Conservation Commons, and the Water Resource Management Commons

Chaffin, Brian C.; Garmestani, Ahjond S.; Angeler, David G.; Herrmann, Dustin L.; Stow, Craig A.; Nystrom, Magnus; Sendzimir, Jan; Hopton, Matthew E.; Kolasa, Jurek; and Allen, Craig R., "Biological invasions, ecological resilience and adaptive governance" (2016). Nebraska Cooperative Fish \& Wildlife Research Unit -- Staff Publications. 229.

https://digitalcommons.unl.edu/ncfwrustaff/229

This Article is brought to you for free and open access by the Nebraska Cooperative Fish \& Wildlife Research Unit at DigitalCommons@University of Nebraska - Lincoln. It has been accepted for inclusion in Nebraska Cooperative Fish \& Wildlife Research Unit -- Staff Publications by an authorized administrator of DigitalCommons@University of Nebraska - Lincoln. 


\section{Authors}

Brian C. Chaffin, Ahjond S. Garmestani, David G. Angeler, Dustin L. Herrmann, Craig A. Stow, Magnus Nystrom, Jan Sendzimir, Matthew E. Hopton, Jurek Kolasa, and Craig R. Allen 
Research article

\title{
Biological invasions, ecological resilience and adaptive governance
}

\author{
Brian C. Chaffin ${ }^{\text {a, }}{ }^{*}$, Ahjond S. Garmestani ${ }^{b}$, David G. Angeler ${ }^{c}$, Dustin L. Herrmann ${ }^{\text {d }}$, \\ Craig A. Stow ${ }^{\text {e }}$, Magnus Nyström ${ }^{\text {, }}$, Jan Sendzimir ${ }^{\text {g }}$, Matthew E. Hopton ${ }^{\text {b }}$, Jurek Kolasa ${ }^{\text {h, }}$ \\ Craig R. Allen ${ }^{\mathrm{i}}$
}

\footnotetext{
a Department of Society \& Conservation, College of Forestry \& Conservation, University of Montana, 32 Campus Drive, Missoula, MT 59812, USA

${ }^{\mathrm{b}}$ National Risk Management Research Laboratory, United States Environmental Protection Agency, 26 W. Martin Luther King Jr. Drive, Cincinnati, OH 45268, USA

${ }^{c}$ Department of Aquatic Sciences and Assessment, Swedish University of Agricultural Sciences, Box 7050, 75007 Uppsala, Sweden

${ }^{\mathrm{d}}$ Oak Ridge Institute for Science and Education Research Participant Program with the United States Environmental Protection Agency, 26 W. Martin Luther King Jr. Drive, Cincinnati, OH 45268, USA

e Great Lakes Environmental Research Laboratory, National Oceanic and Atmospheric Administration, 4840 S. State Road, Ann Arbor, MI 48108-9719, USA

${ }^{\mathrm{f}}$ Stockholm Resilience Center, Stockholm University, Kräftriket 2B, SE-106 91, Stockholm, Sweden

$\mathrm{g}$ Institute of Hydrobiology and Aquatic Ecosystem Management, University of Natural Resources and Applied Life Science (BOKU), Max Emanuel-Strasse 17, A-1180, Vienna, Austria

${ }^{\text {h }}$ Department of Biology, McMaster University, 1280 Main St. West, Hamilton, ON L8S 4K1, Canada

${ }^{\mathrm{i}}$ U.S. Geological Survey, Nebraska Cooperative Fish and Wildife Unit, University of Nebraska 423 Hardin Hall, 3310 Holdrege Street, Lincoln, NE 685830984, USA
}

\section{A R T I C L E I N F O}

\section{Article history:}

Received 13 October 2015

Received in revised form

9 April 2016

Accepted 21 April 2016

Available online 2 July 2016

\section{Keywords:}

Biological invasions

Invasive species

Ecological resilience

Adaptive governance

Adaptive management

Ecosystem services

\begin{abstract}
A B S T R A C T
In a world of increasing interconnections in global trade as well as rapid change in climate and land cover, the accelerating introduction and spread of invasive species is a critical concern due to associated negative social and ecological impacts, both real and perceived. Much of the societal response to invasive species to date has been associated with negative economic consequences of invasions. This response has shaped a war-like approach to addressing invasions, one with an agenda of eradications and intense ecological restoration efforts towards prior or more desirable ecological regimes. This trajectory often ignores the concept of ecological resilience and associated approaches of resilience-based governance. We argue that the relationship between ecological resilience and invasive species has been understudied to the detriment of attempts to govern invasions, and that most management actions fail, primarily because they do not incorporate adaptive, learning-based approaches. Invasive species can decrease resilience by reducing the biodiversity that underpins ecological functions and processes, making ecosystems more prone to regime shifts. However, invasions do not always result in a shift to an alternative regime; invasions can also increase resilience by introducing novelty, replacing lost ecological functions or adding redundancy that strengthens already existing structures and processes in an ecosystem. This paper examines the potential impacts of species invasions on the resilience of ecosystems and suggests that resilience-based approaches can inform policy by linking the governance of biological invasions to the negotiation of tradeoffs between ecosystem services.
\end{abstract}

(c) 2016 Published by Elsevier Ltd.

\footnotetext{
* Corresponding author.

E-mail addresses: brian.chaffin@umontana.edu (B.C. Chaffin), garmestani. ahjond@epa.gov (A.S. Garmestani), david.angeler@slu.se (D.G. Angeler), herrmann. dustin@epa.gov (D.L. Herrmann), craig.stow@noaa.gov (C.A. Stow), magnus. nystrom@su.se (M. Nyström), jan.sendzimir@boku.ac.at (J. Sendzimir), hopton. matthew@epa.gov (M.E. Hopton), kolasa@mcmaster.ca (J. Kolasa), callen3@unl. edu (C.R. Allen).
}

\section{Introduction}

Biological invasions are a common, inescapable part of a globalized world that is continuously modified. Human activity intentionally and unintentionally influences species distributions, introducing species to new environments including degraded and modified environments susceptible to biological reorganization (Rahel and Olden, 2008). Invasive species-non-native species that geographically spread and increase in abundance following initial 
establishment (Lodge et al., 2006)—by affecting ecological processes (Gandhi and Herms, 2010), engineering ecosystem structure (Crooks, 2002) or affecting community dynamics (Yurkonis et al., 2005), can significantly alter ecosystem structure and function that may result in a significant alteration in the provision of ecosystem services. Although there has been a recent shift toward prevention of invasions (Cook et al., 2010; Simberloff, 2013), traditional approaches to managing invasions have been largely reactionary in nature, with a focus on control through mitigation and eradication (Keller et al., 2007; Foxcroft and McGeoch, 2011). This control approach grew out of a dominant narrative that invasions are ecologically, economically and culturally undesirable, and has been reinforced by many documented cases of detrimental, and often highly visible, impacts (Keller et al., 2007).

This traditional view of invasions and associated approaches to management have become increasingly contested as economically inefficient, ecologically (and evolutionarily) ineffective and potentially undesirable in many cases (Angeler et al., 2012; Allen et al., 2013; Lotz and Allen, 2013). Some invasions may have neutral or positive outcomes (both real and perceived) (e.g., Sax et al., 2002), because they either reinforce specific ecosystem functions or provide economic benefit (e.g., Thomsen, 2010; Wallach et al., 2015; Weigel et al., 2016). Failed invasions or those with neutral ecological outcomes may in fact be more common than what has been reported, because invasions with detrimental ecological or economic effects are more likely to be published than studies reporting non-significant effects (Levine and D'Antonio, 2003). Even some invasions initially labeled as socially undesirable may be beneficial to some degree because they provide opportunity to gain a deeper understanding of complex system dynamics (e.g., Bertness and Cloverdale, 2013). Though scientific understanding and technological innovation has and will advance to further support a "detect and eradicate" approach for some invasive species (Simberloff, 2013), new conceptual frameworks for managing invasions are required to address the complexity of invasions (Ricciardi and Atkinson, 2004) especially given the rapid increase in ecological and socioeconomic uncertainties associated with global change.

The concept of ecological resilience, defined as the capacity of a system to withstand change while maintaining processes and structures (Holling, 1973), offers a rich theoretical frame for understanding invasions. In addition, ecological resilience and related concepts can serve as a bridge to new approaches to invasive species management with a focus on understanding ecosystem dynamics as opposed to controlling a single species (Angeler et al., 2015a). Resilience-as a property of complex systems-has inspired a series of theoretical advancements in approaches to governing interactions between society and biophysical systems (Gunderson et al., 2005; Folke, 2006). In this context, 'governance' describes the "social and political process of defining goals for the management of [social-ecological systems] and resolving tradeoffs, and management is defined as the actions taken to achieve these goals and includes monitoring and implementation" (Biggs et al., 2012 citing Pahl-Wostl, 2009). Gaining an understanding of biological invasions in terms of ecological resilience allows for the deliberate engagement with resilience-based approaches to governance (Garmestani and Benson, 2013) that can coordinate the management of invasive species at scales relevant to ecosystems, ecosystem function and the provision of ecosystem services, instead of at anthropocentric scales such as political and jurisdictional boundaries.

In this paper we highlight the potential of adaptive governance, a resilience-based approach that shifts the focus of governance and management actions from reactions toward a single species invasion to a more holistic view of the functional role of invasions in ecosystems. We frame adaptive governance as an approach to managing tradeoffs between ecosystem services, recognizing that the role of invasions in these complex processes may not always be spatially or temporally apparent. Our goal is that this synthesis of scholarship will be a bridge to policy to inform both future empirical research on biological invasions as well as practical applications of resilience-based governance approaches to managing invasive species and associated effects on ecosystem services and human wellbeing.

\section{Ecological resilience and biological invasions}

The concept of ecological resilience emphasizes non-linear change in ecological systems, more specifically, the existence of alternative regimes (Holling, 1973). Once a disturbance threshold is passed, a system can undergo a shift characterized by a relatively abrupt change in structuring processes, reorganizing into a new regime dominated by a different set of processes, structures, functions and feedbacks (represented in the adaptive cycle of complex systems (Holling, 1986); Fig. 1). Undergoing such a regime shift may be unlikely if the system is resilient to the influence of disturbance events (i.e., structuring processes are reinforced by social-ecological feedbacks and cross-scale interactions) (Nyström et al., 2012). However, system-reinforcing feedbacks can be weakened with the addition of novel species, such is the case with biological invasions. Biological invasions can influence ecosystem resilience and threshold dynamics, potentially triggering regime shifts.

In this section we review biological invasions from an ecological resilience perspective, paying particular attention to literature that highlights the importance of scale, invasion success and the role of invasions in building and eroding the resilience of ecosystem regimes.

\subsection{Scale}

Explicit to the concepts of ecological resilience is a cross-scale view of ecosystem structure and dynamics (Garmestani et al., 2009). Scale-specific interactions between patterns and processes and biotic-abiotic feedbacks provide systems with their

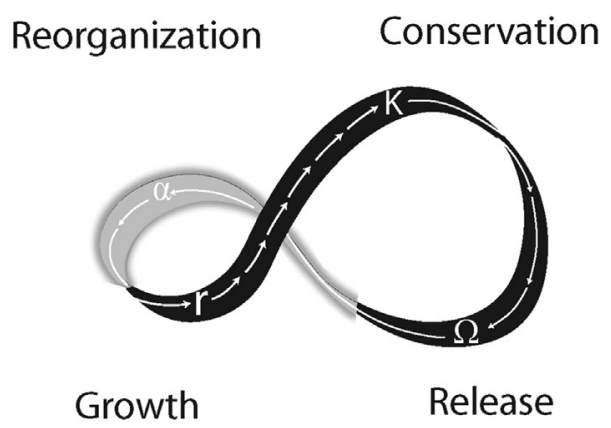

Fig. 1. A representation of an adaptive cycle. The arrows indicate the speed of the cycle where short, closely spaced arrows indicate a slowly changing state and long arrows indicate a rapidly changing state. The cycle reflects changes in two properties: (1) Y axis-the potential that is inherent in the accumulated resources of biomass and nutrients; (2) X axis-the degree of connectedness among controlling variables. Low connectedness is associated with diffuse elements loosely connected to each other whose behavior is dominated by outward relations and affected by outside variability. High connectedness is associated with aggregated elements whose behavior is dominated by inward relations among elements of the aggregates, relations that control or mediate the influence of external variability. Opportunities for invasion are heightened as the cycle transitions from the Omega phase into the onset of the Alpha phase (shown in lighter coloration). Adapted from Panarchy: Understanding Transformations in Human and Natural Systems, L.H. Gunderson and C.S. Holling, eds. Copyright ${ }^{\oplus} 2002$ by Island Press. 
characteristic structure, function and resilience. These sets of structures and functions differ across spatial and temporal scales in a system (Allen et al., 2006) with functional linkages between scales allowing changes in structure and function at one scale to have potential consequences at higher and lower levels of ecosystem organization. Biological invasions provide clear examples of novel species affecting processes and structures at a particular scale with broader cross-scale effects on ecosystems that ultimately lead to a regime shift. Two examples of this include the American red swamp crayfish (Procambarus clarkii), introduced and invasive in Europe and Asia, and the common carp (Cyprinus carpio), invasive in the USA and many locations worldwide. These species have contributed to regime shifts in shallow lakes and wetlands from clear-water to turbid regimes (Matsuzaki et al., 2009). Both species indirectly destabilize shallow lake sediments through burrowing and foraging behaviors (i.e., consuming and mechanically damaging submerged vegetation). Reduced vegetation cover together with re-suspension of sediment (and nutrients from both mechanical action of soil disturbance and decay of damaged vegetation) ultimately destabilizes critical feedbacks that reinforce the clear-water regime, causing a shift to an alternative, turbid regime (Matsuzaki et al., 2009).

The resilience of ecological regimes, including key ecological processes, depends on the distribution of function within and across scales (Peterson et al., 1998). If species of the same functional group operate at different temporal and spatial scales, they provide mutual reinforcement that contributes to the resilience of a function (i.e., redundancy) (Walker, 1992), while minimizing competition among species within the functional group. Resilience is enhanced by imbrications of ecological function among species of different functional groups that operate at the same scales and the response diversity of members of the same functional group within scales (Elmqvist et al., 2003; Carpenter et al., 2006). This cross-scale resilience provides insurance against the inevitable 'surprises' (e.g., drought, floods, disease, etc.) that affect ecosystems at multiple scales (Fischer et al., 2006). Cross-scale interactions can be critically influenced by invasive species, and the cross-scale resilience model (Gunderson and Holling, 2002; Allen et al., 2014) provides a framework for further understanding the relationship between invasions and resilience, which in turn can lend insights to interactions between ecological scales and scales of governance (Green et al., 2014).

\subsection{Resilience and invasion success}

An interesting pattern arising from studies that have investigated biological invasions from the perspective of cross-scale structure is that successful invasive species occur non-randomly in relation to discontinuities in body size distributions (Fig. 2) (Allen et al., 1999). In particular, successfully introduced nonindigenous species occur at the edges of body size classes (Allen et al., 1999), which indicate proximity of a species' ecological niche to scale transition zones. These zones are highly variable in terms of biotic and abiotic processes (Wiens, 1989; Allen and Holling, 2010), and are also associated with other phenomena reflecting biological variability, for example: species extinctions or turnover in the community (Allen et al., 1999); higher population fluctuations (Wardwell and Allen, 2009); and decreasing fitness of individuals within a population (Angeler et al., 2014). Species unsuccessful as invaders, alternatively, tend to have body masses that place them in the middle of size classes (Allen, 2006).

The success of invasions in many cases can also be related to the phase of the adaptive cycle (Fig. 1) displayed by the ecosystem in which the invasion occurs (see Holling, 1986). For example, invasions may not be successful when ecosystems are in the mature

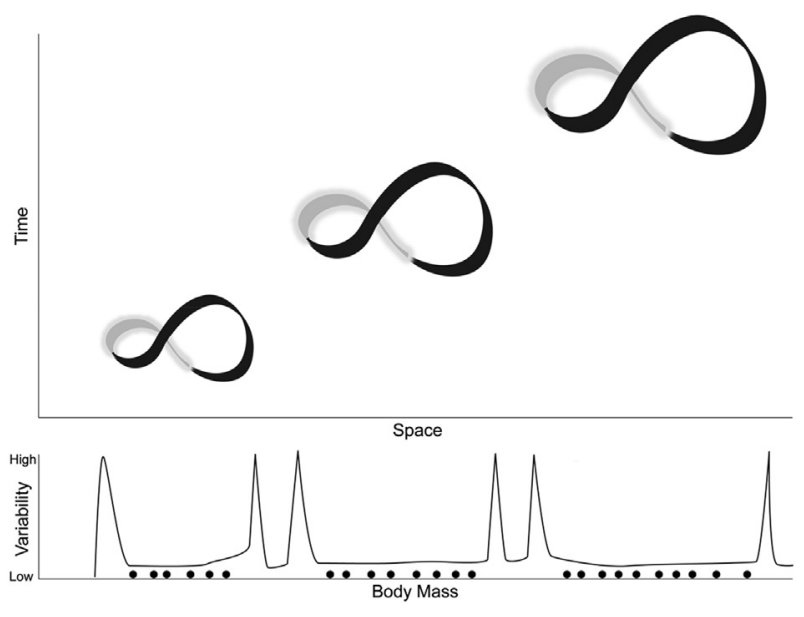

Fig. 2. A representation of a panarchy. A panarchy consists of adaptive cycles (Fig. 1) occurring at different scales of space and time (three dominant scales are represented in this Figure). The three adaptive cycles in the panarchy illustrated provide three discrete scales of opportunity for species to exploit; this is manifest in body mass distributions characterized by aggregations (3) separated by discontinuities. Opportunities for invasion are heightened at the highly variable transition zones between adaptive cycles, manifest as discontinuities in body mass distributions. Additionally, collapse and subsequent reorganization of a panarchy (a regime shift) offers additional opportunities for invasion. Note that the cycles at lower levels occur at smaller spatial scales and are much faster, which the Figure illustrates metaphorically by varying the adaptive cycle size. Adapted from Panarchy: Understanding Transformations in Human and Natural Systems, L.H. Gunderson and C.S. Holling, eds. Copyright ${ }^{\circledR} 2002$ by Island Press.

phase (i.e., in the k-phase of an adaptive cycle) where the niche that an invasive species could exploit is occupied by relatively resilient, resident species. However, the reorganization phase of an adaptive cycle provides a greater opportunity for invasive species to colonize an ecosystem (Fig. 2). It is important to consider that components of an ecosystem can be at different phases of the adaptive cycle and adaptive cycles are nested, meaning that they can display different phases at multiple scales simultaneously. Therefore, invasions can take place at different spatiotemporal scales, mediated by the ecological conditions and processes that characterize each scale. In addition to opportunity during reorganization phases of adaptive cycles, the variability inherent between scales provides heightened variability in resources. This variability can reflect windows of ecological opportunity in the ecosystem that may be exploited by invasive species.

\subsection{Invasive species: building or eroding resilience?}

Despite the consistently applied human narrative of invasions as negative perturbations, invasions are a potential source of novelty, renewal and innovation in ecosystems. Although novelty and innovation can be critical determinants of complex systems dynamics, the consequences of the introduction of novelty and innovation can have varying and disparate effects on ecological resilience depending on context (Gunderson and Holling, 2002). In the same way that genetic mutations affect organisms, invasions can be a source of adaptation or critically destructive in an ecosystem (Allen and Holling, 2010). As such, invasive species are critical for understanding resilience in ecosystems, but also pose an apparent paradox. Invasive species may be incorporated functionally into existing ecosystem processes and structure with little alteration to extant ecosystem dynamics-even potentially enhancing resilience of a regime to avoid regime shifts-or the addition of invasive species may erode resilience causing a transformation in ecosystem structure and function (Almaraz and Oro, 
2011).

Invasions can also facilitate the recovery of a socially desirable ecosystem regime (Jain and Krishna, 2002); for example, the invasion of the European green crab (Carcinus maenas) into degraded salt marshes along Cape Cod in New England, USA (Bertness and Cloverdale, 2013). Overfishing of native predator populations resulted in greatly increased densities of native herbivorous marsh crab (Sesarma reticulatum) populations. Larger Sesarma populations created marshes denuded of vegetation, and these denuded marshes were maintained in the continued absence of predators. The invasive generalist predator Carcinus invaded the denuded marshes as it was able to use the same small burrows as Sesarma, and through direct and indirect predation reduced herbivory by Sesarma. In the absence of heavy herbivory, marsh grasses were able to reestablish the previous ecological regime (Bertness and Cloverdale, 2013).

Another possible outcome of invasions is that invasive species can strengthen the resilience of the regime existing at the time of invasion (regardless of whether or not the regime is 'desirable' for humans). In this case, introduced species reinforce functions already present in the ecosystem. Maintenance of functions within and across spatial and temporal scales, despite potential changes in community composition resulting from invasion, helps to maintain resilience of the invaded ecosystem. The invasive species simply adds to the suite of species providing a specific function (i.e., redundancy), and if extinction occurred, the invasive species may be functionally equivalent. An example of this scenario is the vertebrate fauna of the Everglades region in south Florida, USA. Since the 1950 s vertebrates in the Everglades have experienced declines in the abundances of native species, with as much as $25 \%$ of the vertebrate fauna declining (Forys and Allen, 2002). Declining species span the size range of extant vertebrates (and therefore represent a diversity of functions over multiple scales). The species that have successfully invaded south Florida have a great range in body mass (and size classes), and thus are present at multiple scales (and multiple size classes). However, the overall distribution of function within and across scales is largely unchanged despite extinctions and invasions, and therefore it is likely that the resilience of the system is relatively unchanged (Forys and Allen, 2002). Invasions can replace native species, but do not reduce functional group richness within scales or reduce ecological function across scales (Forys and Allen, 2002). Despite a fundamental change in community composition, the pattern of ecological function within and across scales has been conserved in the Everglades vertebrate community.

Resilience can also be increased by invasive species because structural and functional feedbacks are not only reinforced, but strengthened. The resultant system regime is more likely to absorb stress and disturbances, decreasing the likelihood of undergoing a regime shift. Building resilience can occur when invasive species contribute novel functions that were not present in the ecosystems prior to the invasions. An example of this is the invasive common reed (Phragmites australis) that has been rapidly invading rivers in the western USA. In the Platte River of the Great Plains (Nebraska, USA), the invasion of Phragmites has altered geomorphic processes such as sandbar movement (Nemec et al., 2014). This represents an alternate regime of the system, and an undesirable one for many reasons-and thus the recipient of a \$US 150 million government expenditure for adaptive management of the river. Initially it was thought that the limited management intervention of removing cottonwoods (Populus deltoides) and willows (Salix spp.) could recover lost geomorphic processes (e.g., sandbar movements). However, the recent invasion of Phragmites has deepened a hysteresis effect, so that now extensive and intensive management-Phragmites removal across the entire riparian corridor combined with tree removal and trenching of the substrate to remove root biomass-is required for the river to revert to its previous regime. The Phragmites example is a case where a sequence of multiple invasions of different species has contributed to build the resilience of an altered regime. This example may also describe an ecosystem previously altered by anthropogenic perturbations (e.g., contamination, land use change) unrelated to the invasion under study; these antecedent conditions have provided windows of opportunity for non-native species to successfully invade and incrementally increase the resilience of an altered regime.

Thus, resilience can be reduced by invasions, especially when an invasive species alters structural and functional feedbacks among key processes in an ecosystem causing it to shift to an alternate regime (Table 1). Van Nes and Scheffer (2004) contend that in a world where multiple regimes are possible, gradual changes in environmental conditions (e.g., biological invasions) can reduce the resilience of a desirable system regime. When resilience is low, even a small stochastic perturbation provides a window of opportunity that can trigger a regime shift. For example, paperbark trees (Melaleuca quinquenervia) were introduced to south Florida from Australia for ornamental purposes (Serbesoff-King, 2003). These trees have since become aggressive invaders in North America and begun to dominate areas around the Everglades (Serbesoff-King, 2003). After Hurricane Andrew in 1992, Melaleuca spread at a much greater rate into the Everglades likely as a result of disturbed ecological conditions (Serbesoff-King, 2003). Similarly, coral reef systems typically reorganize after disturbances such as hurricanes, but in the face of increasing natural and human pressures, they can reorganize into alternative regimes (Norström et al., 2009). Although invasive species have not been widely recognized as a problem for coral reefs, invasive species are becoming an issue in areas where reefs are already in decline (Graham et al., 2014). A contemporary example are the Indo-Pacific lionfishes (Pterois volitans and Pterois miles), which have spread across much of the Caribbean since their detection in the early 1990s (Côté et al., 2013). Lionfishes are highly successful competitors and predators of native fishes (Green et al., 2012). Another example is the red macroalgae (Gracilaria salicornia) that was introduced to Hawaiian coral reefs in the 1970s. It has changed the structural complexity of some reefs and caused smothering of many sessile benthic organisms including corals (Martinez et al., 2012).

Invasions can also reduce resilience in less apparent ways. One of the challenges of resilience theory in ecology is that resilience is difficult to quantify, and subtle differences in resilience may not be apparent until it is too late (i.e., an undesirable threshold has been crossed). One source of resilience in systems is in the form of rare species, which constitute an important form of adaptive capacity (Angeler et al., 2015b). Rare and uncommon species may have relatively little to do with the function of a system-until the dynamics of that system change (Walker, 1992). When a system is stressed, by drought for example, formerly uncommon species may become abundant, and become important functional drivers (Walker et al., 1999). Therefore, invasions that come at the expense

Table 1

Potential impacts of biological invasions on the resilience of ecological systems.

\begin{tabular}{ll}
\hline Increase resilience & Decrease resilience \\
\hline Replace lost functions & Loss of ecological function \\
Replace lost ecosystem services & Loss of ecosystem services \\
Increase functional diversity & Decrease in biodiversity \\
Increase cross-scale redundancy & Change in disturbance patterns \\
Increase hysteresis & Initiate trophic cascades \\
Strengthen feedbacks & Decouple feedbacks \\
\hline
\end{tabular}


of rare or uncommon species may have subtle but critically important negative impacts on the adaptive capacity and resilience of an ecosystem.

\section{Governing biological invasions}

The above review of biological invasions through the lens of ecological resilience yields important insights for translating scientific understanding to the action of governing invasions. For example, knowledge of the nested spatial and temporal nature of cross-scale interactions and the current phase of the ecosystem's adaptive cycle, is critical to determine appropriate governance mechanisms (and ultimately management actions) necessary to maintain desired ecosystem regimes. In this section we review the relationship between governance and biological invasions and suggest the processes of adaptive governance as an appropriate path forward.

The concept of environmental governance describes processes through which society (e.g., networks of individuals, organizations and related institutions) determines and prioritizes the use, allocation and conservation of ecological resources. Environmental governance aimed at building ecological resilience to avoid regime shifts works toward either preserving a desired regime through adaptation to disturbances (e.g., preventing or mitigating invasions) or by facilitating the transformation of undesirable regimes toward more desirable ones (e.g., reestablishing key ecosystem services lost as a result of disturbance) (Olsson et al., 2006). A resilience-based framing of environmental governance can inform the choice of management strategies applied to achieve a desired regime amidst complexity and uncertainty (Garmestani and Benson, 2013; Chaffin et al., 2014), which includes managing the impacts and interactions of biological invasions. 'Adaptive governance' describes one resilience-based approach to environmental governance with the potential to inform future efforts to manage biological invasions (Cook et al., 2010).

\subsection{Adaptive governance and adaptive management}

Adaptive governance encompasses a range of formal and informal interactions between individuals, organizations and institutions (e.g., laws, policies, informal rules, social norms) "emerging in pursuit of a desired [regime]" for managing resilience in social-ecological systems (Chaffin et al., 2014). Adaptive governance differs from purely state-based forms of environmental governance in that it is not generally legislated for or explicitly created through hierarchical, command-and-control government processes. Instead, adaptive governance emerges from a novel recombination of institutions and other available resources (e.g., leadership, funding, networks, trust, etc.) following a regime shift at the social-ecological system-scale that has direct implications for governance structures and processes (Chaffin and Gunderson, 2016). Crossed ecological thresholds often trigger societal crises. For example, following a century of overfishing, a narrative of environmental crisis emerged in response to the collapse in stocks of the Atlantic cod (Gadus morhua) fishery that has historically provided ample cod as a food source-a desirable ecosystem service (Harris, 2013). Narratives of crisis can provide the fodder for the recombination of social capital in novel ways toward the emergence of adaptive governance (Chaffin and Gunderson, 2016). For example, mass bleaching of corals in the Great Barrier Reef Marine Park fostered a sense of crisis among the Australian public which influenced new legislation and a broader paradigm shift aimed at managing the park more holistically and based upon a better integration of knowledge on ecosystem dynamics (Olsson et al., 2008). Similar crises may be triggered by invasions, which are considered one of the main factors causing the current biodiversity crisis (Sala et al., 2000).

Transitions toward adaptive governance can be enhanced by properly timed legislation or funding that 1) supports power sharing amongst local resource users and management authorities, and 2) fosters collaborative decision making inclusive of resource users and groups affected by environmental decision making (Dietz et al., 2003; Folke et al., 2005). Adaptive governance represents a shift away from inflexible, centralized government mechanisms toward efforts that: are scaled or "fit" to the nature of ecological problems in question (e.g., basin-scale for watershed related problems) (Rijke et al., 2012); rely on multiple and overlapping authorities and resources to legitimize decision making at more local scales (e.g., redundancy) (Huitema et al., 2009); are focused on system-wide learning and transparent knowledge sharing (PahlWostl et al., 2007); and use the structured processes of adaptive management as a method for determining management actions and subsequent adjustment of policy (Gunderson and Light, 2006). Adaptive management is a structured, iterative process of environmental management that allows managers to make decisions in the face of uncertainty, and fosters social learning through constant monitoring of the system being managed (Holling, 1978; Allen and Garmestani, 2015). Adaptive management is a structured process for testing predictions against empirical data, and subsequently recalibrating management actions at decision points in the adaptive process (Williams, 2011). The process of adaptive management is operationalized by the flexible contexts of adaptive governance, but is also essential for creating the transparent culture of learning and information sharing that is required for resilience-based governance of social-ecological systems (Folke et al., 2005; Chaffin et al., 2014).

\subsection{Invasions and adaptive governance}

We are not the first to suggest an adaptive governance approach to coordinating the management of biological invasions. Cook et al. (2010) proposed a set of design principles for the adaptive governance of invasive species termed "biosecurity governance" with an emphasis on efficiency of information flow and generation of shared information through adaptive management throughout networks of individuals and organizations managing invasive species.

Cook et al. (2010) called for "overlapping complementary biosecurity response capabilities, [that] depart from centralist (or linear) governance structures" and networks of biodiversity collectives for increased attention to local detection and response. In terms of biological invasions, the relevant spatial and temporal scales of governance are invasion dependent-for example, governing the ubiquitous spread of the invasive cheat grass (Bromus tectorum) across the western USA would require a large-scale, landscape approach to governance involving multiple jurisdictions, multiple scales of resource users and multiple levels of government. Foxcroft and McGeoch (2011) suggested adaptive governance as an ideal umbrella policy to coordinate management of invasions across multiple spatial scales and a diverse set of institutions, organizations and authorities. In both cases, the authors were right to call for a more flexible, inclusive process of managing invasions that mirrors the theoretical principles of adaptive governance- -the associated rigidity [of current approaches to governing invasions] does not always allow for the surprises that are common features in dynamic ecological systems" (Foxcroft and McGeoch, 2011). Ideally, the contexts of adaptive governance would provide the adaptive capacity necessary to generate effective responses to biological invasions (including prevention of known potential invaders). However, we argue that the previous 
scholarship calling for adaptive governance of biological invasions-which presumed designed governance structures-ignored the self-organizing nature of adaptive governance. Our approach assumes that the emergence of adaptive governance will include governance mechanisms to ensure fairness and justice in prioritizing the management of invasions at various scales, beyond what Cook et al. (2010) referred to as mechanisms "to achieve the highest ratio of winners to losers within a society." However, this idea represents a critical void in scholarship on adaptive governance generally, and the governance of invasions specifically.

\section{Synthesis}

Our concurrent review of biological invasions, resilience and resilience-based approaches to governance, suggests a shift in focus from design principles for flexibility in managing species, to an approach that manages the resilience of a desired ecosystem regime that includes all species, associated functions and ecosystem services. The emergence of adaptive governance is often a societal response to degradation of economic, cultural or other social benefits provided by ecosystem services (e.g., food production, clean water, raw materials). However, most contemporary approaches to governing biological invasions are overly focused on species makeup as opposed to holistic ecosystem function (e.g., Cook et al., 2010; Foxcroft and McGeoch, 2011). We suggest that one of the key insights for governance, from our review of biological invasions through a resilience lens, is the need to approach the governance and subsequent management of invasions at the regime scale as opposed to an individual species-by-species basis. This equates to developing an adaptive governance approach to maintain desired regimes of ecosystem function, which we suggest can be accomplished by increased attention to the more anthropocentric concept of ecosystem services.

\subsection{Adaptive governance of biological invasions: an ecosystem services approach}

Ecosystem services provide the fundamental basis for human wellbeing and societal development (Daily, 1997); the capacity of ecosystems to produce services is determined by the condition of ecosystems. Some ecosystem services have high direct economic value and are often prioritized in governance, such as food, fiber and fresh water (i.e., "provisioning" services), but their existence builds on the presence of oft neglected "regulating" services (e.g., water and air purification, climate regulation and soil development) and "supporting" services (e.g., primary production and nutrient cycling) (Millennium Ecosystem Assessment, 2005; Carpenter et al., 2006). Generally prioritized to a lesser extent (at least economically) are "cultural" ecosystem services that describe the recreational, aesthetic and spiritual value of ecosystems and biophysical processes. Regime shifts in ecological systems are generally associated with significant changes in ecosystem service production (e.g., Moberg and Folke, 1999), and thus resilience to change in ecosystems plays a key role in this context as it provides stability to the flow of ecosystem services in the long-term under changing conditions (Folke et al., 2004). Maintaining or enhancing resilience of desirable regimes-those that produce the desired combination or amount of ecosystem services for human wellbeing (or reducing resilience of degraded or 'undesirable' regimes)-is a high priority in a society facing unprecedented levels of environmental change and uncertainty. Managing for resilience in socialecological systems for the continued production of critical ecosystem services provides a potential route towards environmental sustainability (Folke et al., 2002).

Taking an ecosystem services approach to governance necessitates that ecosystem services become a critical factor in defining 'desired' ecological regimes - regimes to be maintained by enhancing resilience to disturbance or regimes that are aspired to through active transformation of social-ecological systems. The processes of adaptive governance are a recognized mode of achieving desired regimes in social-ecological systems by providing structure and processes for society to navigate tradeoffs between the use and conservation of ecological resources. These tradeoffs represent prioritized linkages between humans and ecosystem and can be captured in the concept of ecosystem services. Thus, adaptive governance can and should be thought of as the structures and processes that facilitate the societal prioritization and management of ecosystem services, as opposed to management of species composition as in the case of invasive species. Refocusing on ecosystem services may serve to better translate "what society wants' into actionable management that can be informed by ecosystem science. Below we discuss an example from Nebraska, USA to more clearly illustrate this idea.

\subsection{Invasive red cedar and tradeoffs between ecosystem services: The Nebraska (USA) Natural Legacy Project as an approach to adaptive governance}

The state of Nebraska, together with public and private partners (local, federal and NGO), has initiated an adaptive approach to managing prairie landscapes for wildlife habitat (both cultural and supporting ecosystem services) and other prioritized ecosystem services (Schneider et al., 2011). This plan includes active adaptive management, including management of red cedar (Juniperus virginiana) and other native invasive species. Red cedar is aggressively spreading due to a century of natural fire regime suppression (Pierce and Reich, 2010; Schneider et al., 2011). Red cedar invasion of grasslands leads to a loss of grassland wildlife habitat and reduced livestock forage (Schneider et al., 2011). Evidence from the southern Great Plains documents catastrophic collapses in biodiversity following cedar invasion, including a reduction in the abundance of grassland birds, small mammals and pollinators (Limb et al., 2010). Collapses in the diversity and abundance of endemic grassland species following transformation to juniper woodland (cedar) correspond with declines in social-ecological values; specifically, juniper invasions threaten cattle ranching livelihoods. Cattle production can decline significantly after a system transition from grassland to juniper woodland. Juniper invasion also reduces wildfire suppression potential and has been implicated as a major reason for the increase in the frequency and size of wildfires at the wildland-urban interface (Pierce and Reich, 2010). Fire, especially uncontrolled wildfire, is perceived negatively, even though the natural fire regime provides an ecosystem service in controlling cedar invasions (Morton et al., 2010; Harr et al., 2014). The transition between grasslands and cedar forests is non-linear, and both system regimes are generally resilient to change (Pierce and Reich, 2010). Thus, managing these alternate regimes is not only important to public agencies and private organizations vested in maintaining grassland diversity, but also to the interests of the private landowners and members of the public who value ranching livelihoods and recreational opportunities such as grassland bird hunting.

The Nebraska Wildlife Action Plan (part of the Natural Legacy Project) can be described as an adaptive governance approach to maintaining desired ecosystem services in the Great Plains ecosystem by conserving natural habitats (not simply species) and associated human values of those ecosystems (Schneider et al., 2011). Part of the plan calls explicitly for an adaptive management approach to on-the-ground applications to increase the biophysical knowledge (through experimentation) of how to best 
manage cedar invasions. This generally involves experimental approaches such as cutting, fire, herbicides, grazing domestic goats and combinations thereof. The plan recognizes that cedar invasion in the ecosystem is not simply a biological problem, but has as much to do with how people perceive the landscape and structuring processes such as fire (e.g, Morton et al., 2010; Harr et al., 2014). Therefore, the Nebraska Wildlife Action Plan has also provided for scenario-building exercises with a landscape-level group of stakeholders (e.g., ranchers, local communities, land management agencies, local researchers), such that alternative future states of landscapes can be envisioned, and pathways to attain desirable future states are identified collaboratively. These scenario-building exercises create a venue for collective interests in governance to engage in social learning, for example, recognizing tradeoffs in ecosystem services related to the reducing fire in the landscape, increased cedar invasions and decreased viability of cattle ranching. The adaptive approach of the Nebraska Wildlife Action Plan has facilitated social learning among private landowners who previously perceived prescribed fire as an undesirable management alternative. As a result of this learning, community-centered burn associations have been formed and supported throughout Nebraska to reintroduce fire regimes to the landscape (Schneider et al., 2011). Burn associations are locally governed organizations with the sole purpose of enabling community members to help each other burn their grasslands to mimic natural fire regimes, and for members to learn from one another and from the application of associated management actions. These associations, the enabling governance structures (e.g., the Nebraska Wildlife Action Plan) and the social learning resulting from adaptive management, represent an adaptive governance response to manage the social-ecological resilience of Nebraska's prairie grasslands.

\section{Discussion and conclusions}

Biological invasions can decrease resilience of desired ecosystem regimes if the invaders out-compete native species that are critical to maintaining ecosystem services or change ecological processes that can lead to a regime shift (Matsuzaki et al., 2009). Loss of ecological function of the native community (e.g., phytoplankton primary productivity) due to biological invasions may be associated with the loss of certain ecosystem services (e.g., increased bloom formation of invasive, mixotrophic algae that reduces the recreational quality of lakes (Angeler et al., 2012)). Other deleterious effects from biological invasions may include changes in disturbance patterns, in dynamics of trophic cascades and in disruption of the structures and processes that effect biogeochemical cycling in ecological systems (Vitousek and Walker, 1989; Mack and D'Antonio, 1998; Needles et al., 2015). These may contribute to regime shifts towards undesired ecosystem states as well as reinforce the persistence of these states and spur further invasions (Yelenik and D'Antonio, 2013).

Invasions can also build resilience in desired ecosystem regimes and introduce beneficial novelty to maintain these states. Invasive species can replace ecological functions lost with species extinctions in ecosystems (Griffiths et al., 2010), and therefore could replace lost, or complement current, ecosystem services in a desired regime (Thijs et al., 2015). This conclusion should be viewed with caution, however, as there may be a time lag in the effects of invasions on the overall system. Thus, a positive result of an invasion could simply be a short-term 'fix' that eventually results in deleterious effects for the ecosystem in question. Associated with replacing ecological functions, biological invasions can increase functional diversity and cross-scale redundancy, which could increase the resilience of a system. Invasions can reinforce structures and processes, which increase resilience but not necessarily that of a desired regime (Yelenik and D'Antonio, 2013). Invasive species may add functions that do not have deleterious effects, but instead functions that create and enhance adaptive capacity. In a world of increasing transformation in climate and land cover, a deeper understanding of the relationship between invasive species and their effect on adaptive capacity of ecosystems is critical.

There is no doubt that the rapid spread of invasive species has and will continue to have deleterious effects on the structure and function of invaded ecosystems, as well as on the economic and cultural benefits humans receive from these ecosystems. Although invasive detection and eradication technology has improved at breakneck speed, completely stopping the spread of biological invasions remains highly unlikely. The societal challenge instead is to govern the introduction and spread of invasive species in a manner that limits social and ecological losses. Employing an increased understanding of the interaction between invasions and the resilience of ecosystems may lead to an approach to governing invasive species in a more integrated and cost-efficient manner given a renewed focus on understanding and managing ecosystem dynamics as opposed to single species.

Understanding invasions' potential influence on the resilience of ecosystems (and regime shift dynamics) emphasizes the need for a focus on ecosystem services instead of species. Because ecosystem services are multifaceted (i.e., invasions might be beneficial for one service but deteriorate another), there is need to operationalize invasion effects on ecosystem services: invasions of what, to what and for what? This operationalization can facilitate adaptive governance approaches amenable to a constant recalibration and shift in focus of management without being applied prescriptively by targeting the invasive species alone-employing an adaptive management approach to learning and adjusting larger scale governance of invasions. Adaptive governance for biological invasions should focus on function, processes and dynamics at the ecosystem scale, and consider the incorporation of threshold dynamics in decision frameworks of invasive species management and restoration (Gaertner et al., 2012). Adaptive governance in this regard may serve as an improved management approach for hybrid systems like agroecosystems, which can be composed of economically viable invasive species. An adaptive strategy for governing invasions calls for transparency of knowledge, networks, nesting, scale fit, participation and targeted funding using ecosystem services as incentives to collaborate, and crisis as key motivator of changing narratives. Moving forward, there are barriers to implementing an adaptive governance approach to biological invasions, such as legitimacy of process, how to define goals and most importantly, funding for the approach. Despite these barriers, we believe that an adaptive governance approach can be an effective mechanism for dealing with biological invasions in an increasingly connected world.

\section{Acknowledgements}

The Nebraska Cooperative Fish and Wildlife Research Unit is jointly supported by a cooperative agreement between the U.S. Geological Survey, the Nebraska Game and Parks Commission, the University of Nebraska-Lincoln, the U.S. Fish and Wildlife Service and the Wildlife Management Institute. This research was partially conducted with the support of two appointments to the Research Participation Program at the U.S. Environmental Protection Agency National Risk Management Research Laboratory, one administered by the National Academies Research Associateship Program, and one by the Oak Ridge Institute for Science and Education. The views expressed herein are those of the authors and do not necessarily represent those of the U.S. Environmental Protection Agency. We gratefully acknowledge funding from the August T. Larsson 
Foundation of the Swedish University of Agricultural Sciences, the U.S. Geological Survey John Wesley Powell Center for Analysis and Synthesis, the Great Lakes Environmental Research Laboratory (contribution number 1817) and the Swedish Research Councils Formas (2014-1193) and Vetenskapsrådet (2014-5828).

\section{References}

Allen, C.R., 2006. Predictors of introduction success in the south Florida avifanua. Biol. Invasions 8, 491-500.

Allen, C.R., Holling, C.S., 2010. Novelty, adaptive capacity, and resilience. Ecol. Soc. 15, 24.

Allen, C.R., Garmestani, A.S., 2015. Adaptive Management of Social-ecological Systems. Springer, Dordrecht, Netherlands.

Allen, C.R., Forys, E.A., Holling, C.S., 1999. Body mass patterns predict invasions and extinctions in transforming landscapes. Ecosystems 2, 114-121.

Allen, C.R., Garmestani, A.S., Havlicek, T.D., Marquet, P.A., Peterson, G.D., Restrepo, C., Stow, C.A., Weeks, B.E., 2006. Patterns in body mass distributions: sifting among alternative hypotheses. Ecol. Lett. 9, 630-643.

Allen, C.R., Wardwell, D.A., Nemec, K.T., Brust, M., Fogell, D., Hoffman, J.D., Hogue, J., Lotz, A., Miller, T., Pummill, M., Ramirez-Yañez, L.E., 2013. Predictors of regional establishment success and spread of introduced non-indigenous vertebrates. Glob. Ecol. Biogeogr. 22, 889-899.

Allen, C.R., Angeler, D.G., Garmestani, A.S., Gunderson, L.H., Holling, C.S., 2014. Panarchy: theory and application. Ecosystems 17, 578-589.

Almaraz, P., Oro, P., 2011. Size-mediated non-trophic interactions and stochastic predation drive assembly and dynamics in a seabird community. Ecology 92, 1948-1958.

Angeler, D.G., Allen, C.R., Johnson, R.K., 2012. Insights on invasions and resilience derived from spatiotemporal discontinuities at local and regional scales. Ecol. Soc. $17,32$.

Angeler, D.G., Allen, C.R., Vila-Gispert, A., Almeida, D., 2014. Fitness in animals correlates with proximity to discontinuities in body size distributions. Ecol. Complex 20, 213-218.

Angeler, D.G., Allen, C.R., Barichievy, C., Eason, T., Garmestani, A.S., Graham, N.A.J., Granholm, D., Gunderson, L.H., Knutson, M., Nash, K.L., Nelson, R.J., Nystrom, M., Spanbauer, T.L., Stow, C.A., Sundstrom, S.M., 2015a. Management applications of discontinuity theory. J. Appl. Ecol. http://dx.doi.org/10.1111/1365-2664.12494.

Angeler, D.G., Allen, C.R., Uden, D.R., Johnson, R.K., 2015b. Spatial patterns and functional redundancies in a changing boreal lake landscape. Ecosystems 18, 889-902.

Biggs, R., Schlüter, M., Biggs, D., Bohensky, E.L., BurnSilver, S., Cundill, G., Dakos, V., Daw, T.M., Evans, L.S., Kotschy, K., Leitch, A.M., Meek, C., Quinlan, A., RaudseppHearne, C., Robards, M.D., Schoon, M.L., Schultz, L., West, P.C., 2012. Toward principles for enhancing the resilience of ecosystem services. Ann. Rev. Environ. Resour. 37, 421-448.

Bertness, M.D., Cloverdale, T.C., 2013. An invasive species facilities the recovery of salt marsh ecosystems on Cape Cod. Ecology 94, 1937-1943.

Carpenter, S.R., Bennett, E.M., Peterson, G.D., 2006. Scenarios for ecosystem services: an overview. Ecol. Soc. 11, 29.

Chaffin, B.C., Gosnell, H., Cosens, B.A., 2014. A decade of adaptive governance: synthesis and future directions. Ecol. Soc. 19, 56.

Chaffin, B.C., Gunderson, L.H., 2016. Emergence, institutionalization, and renewal: rhythms of adaptive governance in complex social-ecological systems. J. Environ. Manag. 165, 81-87.

Cook, D.C., Liu, S., Murphy, B., Lonsdale, W.M., 2010. Adaptive approaches to biosecurity governance. Risk Anal. 3, 1303-1314.

Côté, I.M., Green, S.J., Hixon, M.A., 2013. Predatory fish invaders: insights from IndoPacific lionfish in the western Atlantic and Caribbean. Biol. Conserv. 164, 50-61.

Crooks, J.A., 2002. Characterizing ecosystem-level consequences of biological invasions: the role of ecosystem engineers. Oikos 97, 153-166.

Daily, G.C., 1997. Nature's Services: Societal Dependence on Natural Ecosystems. Island Press, Washington DC.

Dietz, T., Ostrom, E., Stern, P.C., 2003. The struggle to govern the commons. Science 302, 1907-1912.

Elmqvist, T., Folke, C., Nyström, M., Peterson, G., Bengtsson, J., Walker, B., Norberg, J., 2003. Response diversity, ecosystem change, and resilience. Front. Ecol. Environ. $1,488-494$.

Fischer, J., Lindenmayer, D.B., Manning, A.D., 2006. Biodiversity, ecosystem function, and resilience: ten guiding principles for commodity production landscapes. Front. Ecol. Environ. 4, 80-86.

Folke, C., 2006. Resilience: the emergence of a perspective for social-ecological systems analyses. Glob. Environ. Change 16, 253-267.

Folke, C., Carpenter, S., Elmqvist, T., Gunderson, L.H., Holling, C.S., Walker, B., 2002. Resilience and sustainable development: building adaptive capacity in a world of transformations. Ambio 31, 437-440.

Folke, C., Carpenter, S., Walker, B., Scheffer, M., Elmqvist, T., Gunderson, L.H., Holling, C.S., 2004. Regime shifts, resilience, and biodiversity in ecosystem management. Ann. Rev. Ecol. Syst. 35, 557-581.

Folke, C., Hahn, T., Olsson, P., Norberg, J., 2005. Adaptive governance of socialecological systems. Ann. Rev. Environ. Resour. 30, 441-473.

Forys, E.A., Allen, C.R., 2002. Functional group change within and across scales following invasions and extinctions in the Everglades ecosystem. Ecosystems 5 339-347.

Foxcroft, L.C., McGeoch, M., 2011. Implementing invasive species management in an adaptive management framework. Koedoe 53, 1006.

Gaertner, M., Holmes, P.M., Richardson, D.M., 2012. Biological invasions, resilience and restoration. In: van Andel, J., Aronson, J. (Eds.), Restoration Ecology: the New Frontier. John Wiley \& Sons, Ltd., Chichester, UK, pp. 265-280.

Gandhi, K.J.K., Herms, D.A., 2010. Direct and indirect effects of alien insect herbivores on ecological processes and interactions in forests of eastern North America. Biol. Invasions 12, 389-405.

Garmestani, A.S., Allen, C.R., Gunderson, L.H., 2009. Panarchy: discontinuities reveal similarities in the dynamic system structure of ecological and social systems. Ecol. Soc. 14, 15.

Garmestani, A.S., Benson, M.H., 2013. A framework for resilience-based governance of social-ecological systems. Ecol. Soc. 18, 9.

Graham, N.A.J., Cinner, G.E., Norström, A.V., Nyström, M., 2014. Coral reefs as novel ecosystems: embracing new futures. Curr. Opin. Environ. Sustain 7, 9-14.

Green, O.O., Garmestani, A.S., Hopton, M.E., Heberling, M.T., 2014. A multi-scalar examination of law for sustainable ecosystems. Sustainability 6, 3534-3551.

Green, S.J., Akins, J.L., Maljković, A., Côté, I.M., 2012. Invasive lionfish drive Atlantic coral reef fish declines. PLoS One 7, e32596.

Griffiths, C.J., Jones, C.G., Hansen, D.M., Puttoo, M., Tatayah, R.V., Müller, C.B. Harris, S., 2010. The use of extant non-indigenous tortoises as a restoration tool to replace extinct ecosystem engineers. Restor. Ecol. 18, 1-7.

Gunderson, L.H., Holling, C.S. (Eds.), 2002. Panarchy: Understanding Transformations in Human and Natural Systems. Island Press, Washington, DC.

Gunderson, L.H., Holling, C.S., Light, S.S. (Eds.), 2005. Barriers and Bridges to the Renewal of Ecosystems and Institutions. Columbia University Press, New York.

Gunderson, L.H., Light, S.S., 2006. Adaptive management and adaptive governance in the Everglades ecosystem. Pol. Sci. 39, 323-334.

Harr, R.N., Wright Morton, L., Rusk, S.R., Engle, D.M., Miller, J.R., Debinski, D., 2014 Landowners' perceptions of risk in grassland management: woody plant encroachment and prescribed fire. Ecol. Soc. 19, 41.

Harris, M., 2013. Lament for an Ocean: the Collapse of the Atlantic Cod Fishery. McClelland \& Stewart, Toronto.

Holling, C.S., 1973. Resilience and stability of ecological systems. Ann. Rev. Ecol. Syst. $4,1-23$.

Holling, C.S. (Ed.), 1978. Adaptive Environmental Assessment and Management. John Wiley \& Sons, New York.

Holling, C.S., 1986. The resilience of terrestrial ecosystems: local surprise and global change. In: Clark, W.C., Munn, R.E. (Eds.), Sustainable Development of the Biosphere. Cambridge University Press, Cambridge, UK, pp. 292-317.

Huitema, D., Mostert, E., Egas, W., Moellenkamp, S., Pahl-Wostl, C., Yalcin, R., 2009 Adaptive water governance: assessing the institutional prescriptions of adaptive (co-) management from a governance perspective and defining a research agenda. Ecol. Soc. 14, 26.

Jain, S., Krishna, S., 2002. Large extinctions in an evolutionary model: the role of innovation and keystone species. Proc. Natl. Acad. Sci. U. S. A. 99, 2055-2060.

Keller, R.P., Lodge, D.M., Finnoff, D.C., 2007. Risk assessment for invasive species produces net bioeconomic benefits. Proc. Natl. Acad. Sci. U. S. A. 104, 203-207.

Levine, J.M., D'Antonio, C.M., 2003. Forecasting biological invasions with increasing international trade. Conserv. Biol. 17, 322-326.

Limb, R.F., Engle, D.M., Alford, A.L., Hellgren, E.C., 2010. Tallgrass prairie plant community dynamics along a canopy cover gradient of eastern redcedar (Juniperus virginiana L.). Rangel. Ecol. Manag. 63 (6), 638-644.

Lodge, D.M., Williams, S., MacIsaac, H.J., Hayes, K.R., Leung, B., Reichard, S., Mack, R.N., Moyle, P.B., Smith, M., Andow, D.A., Carlton, J.T., McMichael, A. 2006. Biological invasions: recommendations for U.S. policy and management. Ecol. Appl. 16, 2035-2054.

Lotz, A., Allen, C.R., 2013. Social-ecological predictors of global invasions and extinctions. Ecol. Soc. 18, 15.

Mack, M.C., D'Antonio, C.M., 1998. Impacts of biological invasions on disturbance regimes. Trends Ecol. Evol. 13, 195-198.

Martinez, J.A., Smith, C.M., Richmond, R.H., 2012. Invasive algal mats degrade coral reef physical habitat quality. Estuar. Coast Shelf Sci. 99, 42-49.

Matsuzaki, S.S., Usio, N., Takamura, N., Washitani, I., 2009. Contrasting impacts of invasive engineers on freshwater ecosystems: an experiment and meta-analysis. Oecologia 158, 673-686.

Millennium Ecosystem Assessment, 2005. Ecosystems and Human Well Being: Multiscale Assessments. Island Press, Washington, DC. http://www. millenniumassessment.org/documents/document.356.aspx.pdf.

Moberg, F., Folke, C., 1999. Ecological goods and services of coral reef ecosystems. Ecol. Econ. 29, 215-233.

Morton, L.W., Regen, E., Engle, D.M., Miller, J.R., Harr, R.N., 2010. Perceptions of landowners concerning conservation, grazing, fire, and eastern redcedar management in tallgrass prairie. Rangel. Ecol. Manag. 63, 645-654.

Needles, L.A., Gosnell, J.S., Waltz, G.T., Wendt, D.E., Gaines, S.D., 2015. Trophic cascades in an invaded ecosystem: native keystone predators facilitate a dominan invader in an estuarine community. Oikos. http://dx.doi.org/10.1111/oik.01865.

Nemec, K.T., Chan, J., Hoffman, C., Spanbauer, T.L., Hamm, J.A., Allen, C.R., Hefley, T. Pan, D., Shrestha, P., 2014. Assessing resilience in stressed watersheds. Ecol. Soc. $19,34$.

Norström, A.V., Nyström, M., Lokrantz, J., Folke, C., 2009. Alternative states on coral reefs: beyond coral-macroalgal phase shifts. Mar. Ecol. Prog. Ser. 376, 295-306. Nyström, M., Norström, A.V., Blenckner, T., Eklöf, J.S., Folke, C., Österblom, H., 
Steneck, R.S., Thyresson, M., de la Torre Castro, M., Troell, M., 2012. Confronting feedbacks of degraded marine ecosystems. Ecosystems 15, 695-710.

Olsson, P., Gunderson, L.H., Carpenter, S.R., Ryan, P., Lebel, L., Folke, C., Holling, C.S. 2006. Shooting the rapids: navigating transitions to adaptive governance of social-ecological systems. Ecol. Soc. 11, 18 .

Olsson, P., Folke, C., Hughes, T.P., 2008. Navigating the transition to ecosystem-based management of the great barrier reef, Australia. Proc. Natl. Acad. Sci. U. S. A. 105 9489-9494.

Pahl-Wostl, C., 2009. A conceptual framework for analysing adaptive capacity and multi-level learning processes in resource governance regimes. Glob. Environ. Change 19, 354-365.

Pahl-Wostl, C., Sendzimir, J., Jeffrey, P., Aerts, J., Berkamp, G., Cross, K., 2007. Managing change toward adaptive water management through social learning. Ecol. Soc. 12,30 .

Peterson, G., Allen, C.R., Holling, C.S., 1998. Ecological resilience, biodiversity, and scale. Ecosystems 1, 6-18.

Pierce, A.M., Reich, P.B., 2010. The effects of eastern red cedar (Juniperus virginiana) invasion and removal on a dry bluff prairie ecosystem. Biol. Invasions 12 $241-252$.

Rahel, F.J., Olden, J.D., 2008. Assessing the effects of climate change on aquatic invasive species. Conserv. Biol. 22, 521-533.

Ricciardi, A., Atkinson, S.K., 2004. Distinctiveness magnifies the impact of biologica invaders in aquatic ecosystems. Ecol. Lett. 7, 781-784.

Rijke, J., Brown, R., Zevenbergen, C., Ashley, R., Farrelly, M., Morison, P., van Herk, S., 2012. Fit-for-purpose governance: a framework to make adaptive governance operational. Environ. Sci. Pol. 22, 73-84.

Sala, O.E., Chapin, F.S., Armesto, J.J., Berlow, E., Bloomfield, J., Dirzo, R., HuberSandwald, E., Huenneke, L.F., Jackson, R.B., Kinzig, A., Leemans, R., Lodge, D.M. Mooney, H.A., Oesterheld, M., Poff, N.L., Sykes, M.T., Walker, B.H., Walker, M., Wall, D.H., 2000. Global biodiversity scenarios for the year 2100. Science 287, $1770-1774$.

Sax, D.F., Gaines, S.D., Brown, J.H., 2002. Species invasions exceed extinctions on islands worldwide: a comparative study of plants and birds. Am. Nat. 160, 766-783.

Schneider, R., Stoner, K., Steinauer, G., Panella, M., Humpert, M. (Eds.), 2011. The Nebraska Natural Legacy Project: State Wildlife Action Plan, second ed. The
Nebraska Game and Parks Commission, Lincoln, NE.

Serbesoff-King, K., 2003. Melaleuca in Florida: a literature review on the taxonomy, distribution, biology, ecology, economic importance and control measures. J. Aquat. Plant Manag. 41, 98-112.

Simberloff, D., 2013. Invasive Species: what Everyone Needs to Know. Oxford University Press, Oxford, UK.

Thijs, K.W., Aerts, R., van de Moortele, P., Aben, J., Musila, W., Pellikka, P., Gulinck, H., Muys, B., 2015. Trees in a human-modified tropical landscape: species and trait composition and potential ecosystem services. Landsc. Urban Plan. 144, 49-58.

Thomsen, M.S., 2010. Experimental evidence for positive effects of invasive seaweed on native invertebrates via habitat-formation in a seagrass bed. Aquat. Invasions 5, 341-346.

Van Nes, E.H., Scheffer, M., 2004. Large species shifts triggered by small forces. Am. Nat. 164, 255-266.

Vitousek, P.M., Walker, L.R., 1989. Biological invasion by Myrica faya in Hawai'i: plant demography, nitrogen fixation, ecosystem effects. Ecol. Monogr. 59, 247-265.

Walker, B.H., 1992. Biodiversity and ecological redundancy. Conserv. Biol. 6, 18-23.

Walker, B.H., Kinzig, A., Langridge, J., 1999. Plant attribute diversity, resilience, and ecosystem function: the nature and significance of dominant and minor species. Ecosystems 2, 95-113.

Wallach, A.D., Ripple, W.J., Carroll, S.P., 2015. Novel trophic cascades: apex predators enable coexistence. Trends Ecol. Evol. 30, 146-153.

Wardwell, D., Allen, C.R., 2009. Variability in population abundance is associated with thresholds between scaling regimes. Ecol. Soc. 14, 42.

Weigel, B., Blenckner, T., Bonsdorff, E., 2016. Maintained functional diversity in benthic communities in spite of diverging functional identities. Oikos. http:// dx.doi.org/10.1111/oik.02894.

Wiens, J.A., 1989. Spatial scaling in ecology. Funct. Ecol. 3, 385-397.

Williams, B.K., 2011. Passive and active adaptive management: approaches and an example. J. Environ. Manag. 92, 1371-1378.

Yelenik, S.G., D'Antonio, C.M., 2013. Self-reinforcing impacts of plant invasions change over time. Nature 503, 517-520.

Yurkonis, K.A., Meiners, S.J., Wachholder, B.E., 2005. Invasion impacts diversity through altered community dynamics. J. Ecol. 93, 1053-1061. 